\title{
A DISPUTA PELA DEFESA DOS DIREITOS E OS MOVIMENTOS DAS POLÍTICAS PÚBLICAS PARA QUILOMBO NO BRASIL (1995-2010)
}

\author{
THE DISPUTE FOR THE DEFENSE OF RIGHTS AND THE PUBLIC POLICY \\ MOVEMENTS FOR QUILOMBOS IN BRAZIL (1995-2010)
}

\author{
Lucas Bento da Silva ${ }^{1}$ \\ https://orcid.org/0000-0003-0981-8987 \\ http://lattes.cnpq.br/5611016172643988
}

Recebido em: 20 de agosto de 2019.

Aprovado em: 21 de janeiro de 2020.

RESUMO: Nesse artigo serão analisadas formas de reconhecimento étnico e as disputas territoriais nos casos que compõem o corpus dessa pesquisa e que na prática não estão sendo aplicadas corretamente, devido aos interesses econômicos internos e externos. Além disso, também serão observados e verificados os pontos de vista legal, refletindo a legislação pertinente. A contextualização desta investigação é apresentar e analisar um breve panorama sobre as constituições dos quilombos nas Américas, seu curso, e as políticas públicas dos governos Fernando Henrique Cardoso - FHC, (1995-2002) e Luiz Inácio Lula da Silva - LULA, (20032010). Essa análise segue alguns pontos regulatórios existentes sobre a questão quilombola, como o artigo 68 do Ato das Disposições Constitucionais Transitórias (ADCT) da Constituição federal de 1988, que reconhece a existência dos quilombos no espaço brasileiro.

Palavras-chave: Políticas públicas; Quilombo; Disputa; Território; Movimento.

\begin{abstract}
In this article we will analyze the forms of ethnic recognition and territorial disputes in the cases that make up the corpus of this research and which in practice are not being applied correctly, due to internal and external economic interests. In addition, they will also be legally observed and verified, reflecting relevant legislation." The context of this research is to present and analyze a brief overview about the constitutions of quilombos in the Americas, its course, and the public policies of the governments Fernando Henrique Cardoso - FHC, (1995-2002) and Luiz Inacio Lula da Silva - LULA, (2003 -2010). This analysis follows some existing regulatory points on the quilombola issue, such as article 68 of the Transitional Constitutional Provisions Act (ADCT) of the Federal Constitution of 1988, which recognizes the existence of quilombos in the Brazilian space.
\end{abstract}

Keywords: Public policy; Quilombo; Dispute; Territory; Moveme.

${ }^{1}$ Doutorando em Geografia - Programa de Pós-Graduação em Geografia do Instituto de Estudos Socioambientais (IESA) da Universidade Federal de Goiás (UFG), Goiânia/GO. E-mail: quilombonoticias@gmail.com. 


\section{INTRODUÇÃO}

É de fundamental relevância entender a formação dos quilombos brasileiro e a diversidade territorial espacial, com também é necessário entender os cenários da questão agrária no século XXI e os grupos étnicos ou sociais envolvidos nela. Os quilombos, no decorrer dessa conjuntura, lutaram e lutam para reconstruir identidade e territórios, partindo como ponto de partida o território negro como resistência ${ }^{2}$, sendo assim são fundamentais as políticas públicas para a garantia da desapropriação e titulação territorial. Ainda, são importantes para o seguimento das relações que essas famílias estabelecem com o território e o lugar onde vivem.

As relações de choques, intrínseco a espacialização dos conflitos territoriais e a pertinência da investigação cientifica na análise dos obstáculos da luta pelos territórios quilombolas, demandam a compreensão da territorialização ancestral, econômica, social e histórico que refletiram na segurança dos direitos territoriais e negros. Em um processo conjunto de reparação étnica, econômica, cultural e racial, referente a dívida histórica em relação ao genocídio e à exploração física e psicológica dos indígenas e dos negros no espaço geográfico brasileiro. Esta conjuntura é teorizada neste artigo, torna-se essencial, entretanto, um diálogo introdutório sobre o conteúdo e seu ajustamento na análise teórica da ciência humana.

$\mathrm{Na}$ maior parte dos casos, a percepção espacial da espacialização do agronegócio no capitalismo global, em territórios negros e tradicionais, e a densidade dos fatos, por exemplo; assassinatos, deslocamento forçado, grilagem e conflitualidade nos exigem a concepção de outras categorias, por exemplo, geográficas, o espaço, que é produto da conjuntura social e histórico, com união de relações: poder, cultural, ambiental, formas, funções e redes; o território, o qual é perpassado por uma relação simbólica, étnica, cultural, ancestral, de poder e por conflitos de interesses; e o lugar; que também pode ser o lugar de vivência, cidade, bairro, de troca de ideias e onde se prática trabalho ou outros afazeres. Ressalta-se que tais categorias possibilitarão a compreensão do contexto pesquisado no Brasil.

Assim, a ciência social e humana nos possibilita trata a redefinição das comunidades negras e as problemáticas colocadas sobre os mesmos no espaço geográfico brasileiro. Mesmo com a relevância desse assunto para o espaço brasileiro, pertinente à proporção de africanas negras e negros, brasileiras e brasileiros na constituição econômica, cultural, social e étnica ${ }^{3}$.

Portanto, esta pesquisa pretende contribuir com o diálogo das práxis associado aos quilombos especializados e localizados no Brasil, mediante as categorias geográficas, como já pontuado no parágrafo acima, que se somam para o diálogo conceitual e que poderão somar também para o conhecimento dos territórios negros quilombolas.

Desse modo, com intenção de auxiliar na visibilidade e reconhecimento de direito e políticas públicas pelos grupos conservadores de deputados, governadores, vereadores, prefeitos, evangélica e latifundiária, que vê as terras negras só para fins econômico, invés de vê-la como território de vida, perpassado de relações de amor, de cultura, e da agricultura tradicional para viver, trocar e comercializar, exemplo, em feiras locais de bairros das cidades da região, onde se localiza quilombo.

Logo, deseja-se contemplar alguns eixos de complexidades que justificam o esforço desta

\footnotetext{
2 Conforme Almeida (2010, p. 3) "O território incorpora a identidade coletiva".

3 A reflexão sobre esse tema ainda está em textos produzidos sob pressão da encomenda ou dos embates políticos. Apenas muito lentamente, reflexões de maior fôlego vão se somando em um quadro interpretativo articulado (ARRUTI, 2006, p. 27).
} 
pesquisa sobre este tema. Por essas razões, procura-se definir e dialogar com as principais ciências, econômica, antropológica, sociológica e histórica que estruturam o conhecimento natural do pensamento geográfico e que fundamentam esta investigação, sem pretender, em nenhum momento, esgotar a construção e sistematização dos fatos assumidos. Enfim, o espaço geográfico e a noção de território no contexto estudado.

\section{FORMAÇÃO DOS QUILOMBOS NAS AMÉRICAS}

Teorizar sobre a formação territorial dos quilombos no Brasil é, por uma face, apreender a territorialidade dos territórios negros quilombolas e construir um diálogo interdisciplinar com outras áreas da epistemologia cientifica e, de outra face, proporcionar a análise do conceito de quilombo, sua cultura, sua religião, sua economia e sua espacialização, enquanto diversidade espacial e territorial na América Latine e Caribe. Nessa conjuntura, existem inúmeras formas de descrição e formação temporal do passado dos quilombos, não significam conhecer totalmente - sendo assim, como muitas são conhecidas hoje.

Dessa maneira, além dos colonizadores europeus que financiaram as rotas transatlânticas do tráfico negreiro, não podemos esquecer o papel da Igreja católica neste contexto, da contribuição na escravização e marginalização do negro na sociedade brasileira. A Igreja legitimou a escravização das etnias africanas alegando, entre outras questões, que todos eram "infiéis" por terem suas religiões, portanto, a forma de "purgar" os seus "pecados" seria a escravização dos africanos.

Porém, houve resistência e conflitos contra esse sistema, ocasionando fugas constantes das fazendas pelos negros, que se escondiam, em algumas situações, em áreas com matas fechadas ou próximas às cidades. No processo da formação espacial brasileiro, essas áreas foram se consolidando e dando origem às formas dinâmicas de ocupação e, por diversas interpretações, no decorrer dos séculos, esses territórios foram conceituados como quilombo ou mocambo.

O conceito de quilombo, conforme a interpretação do Conselho Ultramarino de 02 de dezembro de 1740, é de que os quilombos são "toda habitação de negros fugidos que passem de cinco, em parte despovoada, ainda que não tenham ranchos levantados nem se achem pilões neles" (SILVA, 2008, p. 73). Isso é a partir de uma norma estabelecida globalmente para definir padrões pelos conjuntos de regras e funções com o objetivo colonial

A interpretação de quilombo pelos europeus influenciou muitos cientistas nos séculos XIX, e com ênfase no XX, cristalizando as formações de quilombos só no sentido histórico, já que na maioria das vezes as construções científicas eram e ainda são eurocêntricas no Brasil. Não houve nesta geração de cientistas uma preocupação e entendimento geográfico das diferentes formas de apropriação dos territórios pelos quilombolas, suas dinâmicas culturais e territoriais específicas, assim como Arthur Ramos e Edson Carneiro que contribuíram para a cristalização da existência dos quilombos em um dado período da história (SILVA, 2008, ).

Os quilombos representaram e representam uma dinâmica importante para entendermos algumas formas de resistências e conflitos contra o sistema hegemônico que existiram e ainda existem no Brasil. Inclusive após a abolição, já que continuaram a representar essa resistência, a visibilidade dos territórios negros quilombolas, o território estratégico onde se juntavam as pessoas de ascendência africana, mas também os indígenas e as ascendências de europeus excluídos. Conforme diz Rafael Sanzio Araújo dos Anjos (2005) quando se refere à questão dos quilombos; 
Constitui uma das questões emergências e estruturais da sociedade brasileira atual. É inconcebível realizarmos leituras do nosso território, de dimensões continentais e diversidade étnica particular, sem contemplar a geografia dos quilombos (ANJOS, 2005, p. 338).

Os significados de quilombo provêm da palavra Kilombo da língua banto umbundo, a qual possui conotações diferentes no Brasil e em outros países das Américas. Tal palavra, falada pelo povo avimbundo, refere-se a um tipo de instituição sociopolítica militar conhecida na África Central, mais especificamente na área formada pela atual República Democrática do Congo (antigo Zaire) e Angola. Apesar de ser um termo umbundo, constitui-se de um agrupamento militar composto pelos jaga ou imbangala (de Angola) e os lunda (do Zaire) no século XVII.

Em outros países das Américas, há outras denominações para os quilombos: na Colômbia e Cuba são os palenques; cumbes na Venezuela; marrons no Haiti e em outras ilhas do Caribe francês; comunidades de cimarrones, em muitas partes da América espanhola, e maroons na Jamaica, no Suriname e no sul dos Estados Unidos 4 . O território ancestral rural dos Palenques de San Basilio está localizado a sessenta quilômetros da cidade de Cartagena, capital do departamento de Bolívar, Caribe Colombiano, o "Palenque foi o primeiro território negro livre das Américas, em 1691” (OLIVEIRA, 2014, p. 80). Segundo Clóvis Moura,

Na Colômbia, Cuba, Haiti, Jamaica, Peru, Guianas, finalmente onde quer que a escravidão existisse, o negro marrom, o quilombola, portanto, apareceu como sinal de rebeldia permanente contra o sistema que o escravizava. Em Cuba, eram os palenques, muitos deles famosos (MOURA, 1993, p. 11).

Essas nomeações marrons, quilombos, palenques, entre outros, foram inseridas em documentos nos períodos coloniais normalmente de forma pejorativa. Os processos geográficos desses territórios, nos vários países das Américas, se deram de formas bastante distintas. Suriname e Jamaica, por exemplo, tiveram tratados de paz com os poderes coloniais, as comunidades rurais negras, como Saramacá, Djuka, Paramaka, Matawai, Aluku e Kwinti, eram compostas por uma estrutura política própria e, por intermédio de seus respectivos reis, mantinham com a ex-colônia relações comerciais, assim puderam, ao longo de sua história, expressar-se efetivamente com base dos seus códigos culturais, sociais e políticos (SOUZA, 2008, p. 29).

O fluxo de negros e negras para as Américas foi constante nos séculos anteriores, e o Brasil foi o país que mais recebeu escravizados oriundos das regiões costeiras do continente africano. Mas, como em outros países das Américas onde o regime de escravidão se instalou, no Brasil também existiu grande resistência e insurreições, porque os escravizados, que não aceitavam serem submetidos aos senhores de engenhos e cafezais, recorriam às fugas em massa dessas fazendas e em alguns casos ocasionavam queimadas nesses lugares.

Ainda, no Brasil, existiu a formação de quilombos do sul ao norte e um dos que mais se destacou na história pela sua organização de territórios foi o Quilombo dos Palmares, localizado na Serra da Barriga em Alagoas. Vale ressaltar que sua importância decorre da luta tenaz que os negros mantiveram em defesa da sua liberdade e cultura, contra o colonizador, enfrentando tropas holandesas e portuguesas, para manterem os territórios étnicos que haviam con-

\footnotetext{
${ }_{4}$ Maroon e marron derivam do Espanhol cimarrón, nome dado pelos primeiros colonizadores das Américas ao gado doméstico fugido para as montanhas da então Ilha de Hispaniola (hoje Haiti e Santo Domingo) - Alguns defendem que o termo quer dizer mocambo.
} 
quistado e organizado.

Desta forma, a denominação dos quilombos no Brasil, desde a Constituição Federal de 1988, tem passado por várias críticas, devido à visão reduzida dos quilombos, o que se retrata na invisibilidade dos mesmos na atualidade. Antes da formulação da Constituição, movimentos negros e sociais já lutavam por seus Direitos, mas desde 1988, os movimentos quilombola, negro e outros movimentos sociais (tanto do campo quanto na cidade) juntamente com alguns autores começaram a dialogar mais sobre as políticas públicas referentes às certificações, titulações e desapropriações de territórios "particulares", que em verdade são territórios grilados, porque as donas são as famílias quilombolas, as quais estão há séculos na territorialidade étnica da desconstrução e construção das suas ancestralidades, que se relaciona com a identidade que essas famílias têm com o território e recursos naturais existentes no local.

Desta forma, a seguir veremos as ações políticas dos governos Fernando Henrique Cardoso - FHC e Luiz Inácio Lula da Silva - LULA, no intuito de analisar como cada governo, a partir de sua práxis e ideologia, construiu e sistematizou as políticas públicas de Estado para os quilombos. Sem dúvida, os dois governos foram relevantes, no entanto, totalmente diversos na concretização e transformação real de políticas.

\section{As dinâmicas das políticas públicas para quilombos nos governos FHC (1995-2002) e LULA (2003-2010), invisibilidade, luta pela garantia dos direitos, limites e desafios}

Discorrer a respeito do espaço brasileiro é dialogar sobre a diversidade sociocultural e os conflitos que existem no espaço geográfico ${ }^{5}$ das Américas. É repensar o contexto histórico dos conflitos atuais e as diversas dinâmicas de organização presentes no território nacional, contrapondo-as aos modelos de monopólios da terra, degradação do meio ambiente e uso de trabalho escravizado contemporâneo, tanto no passado histórico como no tempo atual. A partir da Constituição Federal Brasileira de 1988, foram firmados os "direitos de reconhecimento" daqueles que sempre foram ameaçados em lutas pela legitimação dos seus territórios, isto é, dos quilombos.

A imensa diversidade sociocultural do Brasil é acompanhada de uma extraordinária diversidade fundiária. As múltiplas sociedades indígenas, cada uma delas com formas próprias de inter-relacionamento com seus respectivos ambientes geográficos, formam um dos núcleos mais importantes dessa diversidade, enquanto as centenas de remanescentes das comunidades dos quilombos, espalhadas por todo o território nacional, formam outro (LIT'TLE, 2002, p. 2).

No entanto, os quilombolas nunca tiveram seus direitos respeitados pela elite política e econômica brasileira, por exemplo, a lei 601 de 1850, conhecida como a Lei de Terras, que foi um dos instrumentos jurídico fundamental para que negros, indígenas e camponeses fossem excluídos do acesso a terra, assim, institui-se a propriedade sobre a terra só pela compra, assim, não tendo outra condição para obtê-la. Tal Lei possibilitou que muitos latifundiários agissem de forma violenta contra os grupos sociais e étnicos, que estavam ou estão há décadas nos territórios. Outra estratégia comum que se estende até os dias atuais são as grilagens, cuja

\footnotetext{
${ }^{5}$ De acordo com Moreira (1981), o espaço geográfico é, a um só tempo, resultado e agente impulsor do desenvolvimento da história dos seres humanos. Ora, o processo de desenvolvimento é processo de acumulação.
} 
finalidade era de falsificar os documentos de propriedade sobre a terra e colocar numa gaveta com grilos para ficar com estado de velho.

A partir dos diferentes recursos históricos e atuais para garantir a invisibilidade dos quilombos e de seus direitos no Brasil, pode-se dizer que na formação histórica brasileira, no decorrer do tempo, existiram teorias sociais que diziam, e ainda dizem, haver no Brasil harmonia nas relações sociais, quanto à pluralidade étnica, mas que são contestadas pelas experiências cotidianas de grande parte da população. Deste modo, este conjunto de elementos dos fatos é formado no sentido da invisibilidade e para ocultar a existência dos negros no Brasil.

Além disso, autores como Gilberto Freyre e Nina Rodrigues, entre outras e outros, contribuíram para tal invisibilidade, já que no contexto da formulação das políticas públicas para quilombo, por exemplo, a maioria dos técnicos dos órgãos dos governos, municipais, estaduais e federais achavam que não existiam mais quilombo - o seu imaginário temporal sobre quilombo ainda é o do século XVI, fato que também soma com a dificuldade de compreensão do processo da construção das garantias de direitos e da aplicabilidade das políticas em territórios negros rurais no Brasil.

Ainda, essas teorias ganharam força com o mito da democracia racial, pois, ao contrário de outros países, no espaço brasileiro existe uma convivência pacífica nas relações étnico-raciais e a crença de que todos e todas teriam a mesma oportunidade de sucesso, assim como afirmava Gilberto Freyre, e ,com mais força de que todos, que também reforçou que a mestiçagem, o hibridismo, e até mesmo (mistificação à parte) a plasticidade cultural da convivência entre contrários, como sendo não apenas uma característica, mas uma vantagem do Brasil (FREYRE, 2003 p. 29). No entanto, aponta Edgardo Lander:

Os diferentes recursos históricos (evangelização, civilização, o fardo do homem branco, modernização, desenvolvimento, globalização) têm todos como sustento a concepção de que há um padrão civilizatório que é simultaneamente superior e normal. Afirmando o caráter universal dos conhecimentos científicos eurocêntricos, abordou-se o estudo de todas as demais culturas e povos a partir da experiência moderna ocidental, contribuindo desta maneira para ocultar, negar, subordinar ou extirpar toda experiência ou expressão cultural que não corresponda a esse dever ser que fundamenta as ciências sociais (LANDER, 2005, p. 14).

Em tais condições, atualmente, os quilombos, que se expressam pelas suas etnias, línguas e saberes tradicionais, não estão fora dessa crítica, mas também ligados às complexidades da questão agrária no Brasil. Assim, enfrentam a espacialização e territorialização do agronegócio e das disputas pelos recursos naturais que existem em seus territórios. Também resistindo à barbárie, com ou sem o apoio do Estado, representado pelas elites locais que confiscam e remanejam diversos grupos familiares e mantêm uma estratégia de genocídios dos quilombolas e outras populações tradicionais de suas terras.

Neste sentido, a classificação dos quilombos vai ganhando visibilidade no contexto nacional, devido à luta constante dos movimentos socioterritoriais negros do campo e da cidade por reconhecimento das culturas, dos territórios, dos recursos naturais e das simbologias que caracterizam as ancestralidades nas territorialidades quilombolas. Outra questão central, que motivou o conflito pelo reconhecimento e pela política pública para quilombos, é que a partir da Constituição de 1988 é apresentado no artigo 68 do Ato das Disposições Constitucionais Transitórias - ADCT que: "Aos remanescentes das comunidades quilombolas que estejam ocupando suas terras é reconhecida a propriedade definitiva, devendo o Estado emitir-lhes os

PRACS: Revista Eletrônica de Humanidades do Curso de Ciências Sociais da UNIFAP https://periodicos.unifap.br/index.php/pracs ISSN 1984-4352 Macapá, v. 13, n. 2, p. 211-227, jul./dez. 2020 
títulos respectivos".

Por isso, a partir dos anos 90, os movimentos socioterritoriais, como o Conselho Nacional dos Seringueiros - CSN; o Movimento Interestadual das Quebradeiras de Coco Babaçu MIQCB; o Movimento Nacional dos Pescadores - MONAPE; Coordenação Nacional de Articulação das Comunidades Negras Rurais Quilombolas - CONAQ, o Movimento dos Ribeirinhos da Amazônia; Contra a Discriminação Racial - MNUDCR, conhecido em finais da década de 1980 como Movimento Negro Unificado - MNU; e outros movimentos sociais, organizaram-se para concretizar ações e dialogar com as instâncias governamentais em busca de políticas públicas eficazes para a titulação formal de suas terras.

Sendo assim, procuraremos traçar um breve panorama do contexto atual dessas políticas públicas, desde os sujeitos sociais que se organizam em movimentos coletivos para reivindicálas junto ao Estado até os quilombolas. E também analisaremos a institucionalização e a burocratização de alguns setores privilegiados, situando no tempo as leis direcionadas para comunidades tradicionais e quilombos que são vigentes no território brasileiro. Assim, os Estados, de acordo com a normativa internacional dos Direitos Humanos e seus respectivos ordenamentos jurídicos, devem desvendarem os problemas de propriedade de terras ancestrais habitadas por gerações de afrodescendentes quilombolas e também promoverem a utilização funcional da terra e o desenvolvimento abrangente destas comunidades, respeitando sua cultura e suas formas específicas de tomada de decisão. Ainda, tal normativa solicita que os Estados reforcem as medidas e políticas públicas em favor das mulheres, homens e jovens de origem africana, dado que o racismo os afeta de forma mais profunda, colocando-os numa condição de maior marginalidade e em situação de desvantagem.

A partir disso, o próximo tópico tem por objetivo compreender os principais eixos das políticas públicas, com viés para o campo que utiliza o enfoque territorial no espaço geográfico brasileiro e colombiano nas últimas décadas. Portanto, essas políticas adotaram o recorte territorial como elemento central, que visa reduzir a pobreza, a desigualdade, os conflitos por terra e território, os conflitos étnico-raciais e a pilhagem dos recursos territórios. Particularmente, essas políticas compensatórias, materializadas e espacializadas, estão politicamente em diversos países latino-americanos e caribenhos com metas e ações múltiplas como no Brasil.

\section{Governo FHC}

As ações dos movimentos socioterritoriais negros ao decorrer do tempo vem ganhando totalidade e algumas pautas começam a ser discutidas em âmbito nacional, mas com especificidades e práticas regionais, como nos Estados do Maranhão, Bahia, Pará e São Paulo que são pioneiros nas políticas de titulação de territórios quilombolas. No entanto, nas políticas públicas no governo de Fernando Henrique Cardoso - FHC, 1995 a 2002, na década de 1990, existiram algumas situações singulares e com práticas localizadas, como varemos nos parágrafos seguintes.

Para Viviane Cristina Pinto, "nos primeiros anos, as instituições públicas de cultura sofreram profundas mudanças e as políticas culturais perderam o status de política ministerial em nome do descomprometimento do Estado com as demandas culturais e da contenção de gastos" (PINTO, 2010, p. 13). Porém, no começo de 1995, os movimentos socioterritoriais negros e quilombolas partiram para a luta de reconstrução institucional da política pública com a recriação do Ministério da Cultura - MinC. 
Tal processo, durante os anos 1990, atravessou também diversos setores. A modernização dos museus nacionais, os programas do patrimônio histórico, artístico e cultural, a recente política do patrimônio imaterial e a política para o cinema merecem acento pelas inovações institucionais que significaram na época (PINTO, 2010, p. 13).

Mas, nos dois mandatos dos governos de FHC, percebem-se poucos avanços referente ao orçamento direcionado às políticas para territorialidades quilombolas ou destinada a dialogar e resolver a questão da desigualdade racial e a demanda cultural brasileira, sendo que o Brasil é um dos países com mais diversidade de expressões simbólicas, musicais, religiosas etc. Então quando verificamos o período de 1995 a 2002, assim como aponta Viviane, nota-se que a unidade de programas e ações do Estado: Em geral de forma continuada no tempo, que tem como objetivo o atendimento de necessidades e direitos sociais fundamentais que afetam vários dos elementos que compõem as condições básicas de vida da população, inserem a temática da desigualdade racial, mas não há gastos significativos destinados a garantir essas demandas por maior igualdade, que passa a se tornar cada vez mais evidente, por causa da organização dos movimentos sociais, em especial o negro e o agrário (MARINHO, 2014, p. 7).

No começo de 1995, por exemplo, em função da luta constante dos movimentos socioterritoriais negros e sociais, como também da comemoração da morte de Zumbi dos palmares, alguns militantes do movimento quilombolas encontraram com FHC com o objetivo de solicitar presença na agenda pública, por isso, consequentemente, foi criado o Grupo de Trabalho Interministerial - (GTI) para Valorização da População Negra. Em 1996, foi apresentado o Programa Nacional de Direitos Humanos - PNDH I, onde o governo tentou realizar estratégias de combate às desigualdades raciais através das políticas específicas para a população negra, com a promessa de elaboração de políticas compensatórias que promovessem social e economicamente a comunidade negra (MARINHO, 2014, p. 7).

Dentre as ações promovidas, é importante destacar as ações da Fundação Cultural Palmares - FCP, entidade vinculada ao Ministério da Cultura e do Memorial Zumbi, criado em agosto de 1988, que lutavam pela preservação da Serra da Barriga, em Alagoas, na região nordeste do Brasil. A FCP foi à primeira entidade federal criada para promover a preservação, proteção e disseminação da cultura negra no espaço brasileiro, além disso também tem por finalidade promover a cultura afro-brasileira e a valorização das manifestações de matriz africana, além do mais, formula e implanta políticas públicas que potencializam a participação da população negra brasileira nos processos de desenvolvimento do país.

Ainda, com relação às políticas públicas para quilombos nos governos de FHC, também foram construídos obstáculos no sentido das dúvidas acerca do que seriam quilombos, promovendo dentro da temática étnico-quilombola discussões e conflitos de variados interesses e segmentos da política, da universidade, dos quilombolas e da sociedade civil sobre esses grupos étnicos estruturados de ancestralidades e saberes tradicionais espacializados nas cinco regiões brasileiras. É importante ressaltar que tais limites, desafios e dificuldades são estratégias de manter em oculto a verdadeira história do Brasil, as intenções e a relevância dos grupos étnicos quilombolas na formação do espaço brasileiro.

Desse modo, essa dificuldade inicial é o que teria impedido melhores resultados para a titulação de tais quilombos. Entre 1995 e 1998, apenas 8 títulos foram concedidos, entre 1999 2200238 títulos. De acordo com Marinho (2010), até 2003, a titulação ocorreu de forma isolada, a partir de iniciativas locais, especialmente na Bahia, pelo Instituto de Terras da Bahia - ITERBA; Instituto Nacional de Colonização e Reforma Agrária - INCRA; Fundação Cul- 
tural Palmares - FCP; Secretaria de Estado de Habilitação e Assuntos Fundiários-RJ SEHAF; Instituto de Colonização e Terras do Maranhão - ITERMA; Coordenação de Desenvolvimento Agrário - CDA - BA; Instituto de Terras do Estado de São Paulo - ITESP; IDATERRA: Instituto de Desenvolvimento Agrário e Extensão Rural de Mato Grosso do Sul; Secretaria de Patrimônio da União - SPU e no Instituto de Terras do Piauí - INTERPI. Alguns desses institutos, como o ITESP em São Paulo, ainda emitem título para quilombo, mas em território público.

Os números de titulações de quilombos nos governos FHC de 1995 a 2002 retratam que as políticas públicas para quilombo ficaram apenas em iniciativas localizadas, através das entidades pioneiras do processo de reconhecimento étnico territorial dos quilombolas. Já em 2002, foi criado o PNDH II, com objetivo de criar fundos de reparação social direcionados a financiar "políticas de ação afirmativa e de promoção da igualdade de oportunidades, na mesma ocasião foi lançado o Programa Nacional de Ações Afirmativas sob a coordenação da Secretaria de Estado dos Direitos Humanos do Ministério da Justiça" (MARINHO, 2014, p. 11). Nesse programa nacional, foram acrescentadas as seguintes metas:

Apoiar o reconhecimento, por parte do Estado brasileiro, de que a escravidão e o tráfico transatlântico de escravizados constituíram violações graves e sistemáticas dos direitos humanos, que hoje seriam considerados crimes contra a humanidade; apoiar o reconhecimento, por parte do Estado brasileiro, da marginalização econômica, social e política a que foram submetidos os "afrodescendentes" em decorrência da escravidão; estudar a viabilidade da criação de fundos de reparação social destinados a financiar políticas de ação afirmativa e de promoção da igualdade de oportunidades 6 .

Desta maneira, no decorrer dos governos FHC, ainda foram criados o Programa Brasil Gênero e Raça pelo Ministério do Trabalho. Além disso, foram criados os Ministérios da Justiça e do Desenvolvimento Agrário, como também o Conselho Nacional de Combate à Discriminação, tendo como função propor políticas afirmativas e o Programa Diversidade na Universidade e das Relações Exteriores, o qual instituiu ações afirmativas em suas pastas. E mesmo com essas ações, "ainda na agenda do governo FHC, envolvendo diversos órgãos governamentais, a temática racial encontrava-se vinculada à agenda da Secretaria dos Direitos Humanos e nenhum programa específico para a população quilombola havia sido desenhado" (MARINHO, 2014, p. 11). Para Márcia Lima (2010), as ações afirmativas que ocorreram na gestão FHC foram tímidas e posteriores a Durban 7 tiveram certo enfoque e houve um esforço discursivo de compreender a situação estrutural dos negros e negras mediante produção de diagnósticos e ações reais de implantação de políticas valorativas, no entanto, não houve investimentos no aspecto redistributivo.

Então, as políticas relacionadas à desigualdade racial não estruturavam nos gastos públicos. Isso significa dizer que as políticas neste período não atendiam às demandas por mais igual-

\footnotetext{
${ }^{6}$ Disponível em: <http://portal.mj.gov.br/sedh/pndh/pndhII/Texto\%20Integral\%20 PNDH\%20II.pdf> Acesso em: 3 de jan. de 2018.

${ }^{7} \mathrm{O}$ foco nas ações afirmativas, enquanto constituintes de políticas sociais, ocorreu apenas a partir do interesse de participação do Brasil na III Conferência Mundial de Combate ao Racismo, Discriminação Racial, Xenofobia e Intolerância Correlata promovida pela ONU em 2001, na cidade de Durban, África do Sul. A Declaração e o Programa de Ação de Durban propõem medidas concretas e abrangentes para combater o racismo, a discriminação racial, a xenofobia e as demais formas relacionadas de intolerância (MARINHO, 2014, p. 11).
} 
dade, seja de oportunidade ou de resultados (MARINHO, 2014) ou seja pela impossibilidade de ganhar a vida por conta própria em decorrência de fatores externos (como o racismo, a discriminação de gênero, a inclusão periférica, por exemplo), que são reforçadas pelos meios de comunicações e por parlamentares racistas, homofóbicos e machistas. Tais parlamentares parecem ter apenas o objetivo de acumular capitais por meio de dinheiro dos cofres públicos e, em decorrência disso, as políticas para quilombos nesse período não foram prioridade. Assim como não foi prioridade a implementação de programas e de ações efetivas. Nesse momento, os gastos públicos sintetizam-se aos dados coletados das políticas setoriais como Trabalho, Renda, Desenvolvimento Rural, Educação, Cultura, Assistência Social e Previdência.

\section{Governo Lula}

Já no governo de Luiz Inácio Lula da Silva - LULA, 2003 a 2010, as políticas públicas para quilombos tomaram outros rumos, uma mudança profunda não só na condução das políticas com perspectiva racial, reflexo das ondas de Durban, mas também na relação do Movimento Negro com o Estado. Até então, essa relação era de exterioridade e com os atores na condição de demandantes e com pouca inserção no aparato governamental (LIMA, 2010).

As ações e os programas nos governos LULA para quilombos são mais visíveis e concretos. Ao longo deste trabalho, procura-se localizar as formas de intervenção do Estado por meio de seus objetivos. No sentido de sistematização dessas ações, dividimos em três grupos, o primeiro grupo de políticas pode ser considerado como medidas de caráter repressivo ${ }^{8}$, o segundo grupo está relacionado com as demandas por reconhecimento com intuito valorativo/ identitário ${ }^{9}$ e, por fim, e o terceiro grupo envolve o reconbecimento com intuito redistributivo ${ }^{10}$ (LIMA, 2010). Como observamos, os programas e ações envolvem diversas áreas, assim, focalizaremos nosso debate sobre as políticas para territórios quilombolas nos governos LULA.

$\mathrm{Na}$ década de 1970, alguns militantes negros de diversas organizações fundaram o Movimento Negro Unificado - MNU, com o intuito principal de denunciar as barbáries do Estado brasileiro contra a população negra e as diversas formas de discriminação racial existentes na sociedade. Assim, a fundação do MNU e a multiplicação da mobilização das populações negras urbanas e rurais no território nacional resultaram em maior pressão por políticas compensatórias, que incluíam o respeito à diferença étnica na lista de demandas fundamentais.

Alguns anos mais tarde, em 1988, a Assembleia Nacional Constituinte - eleita pelo voto popular - significou um fator fundamental para diversos aspectos da complexa organização política no Brasil e, dentre esses aspectos, destacamos como relevante a questão quilombola. Ainda, enfatizamos que há em anexo à Carta Magna dessa Constituição alguns artigos que fundamentam as políticas afirmativas, como já citado: o artigo 68 do Ato das Disposições Constitucionais Transitórias.

Além disso, podemos notar que as políticas públicas para os territórios quilombolas até o presente momento, são políticas construídas por meio de diversas relações entre os Ministérios, os movimentos sociais (nesse caso, principalmente o Movimento Quilombola e o Movi-

\footnotetext{
${ }^{8}$ Que se orientam contra comportamentos e condutas discriminatórias, apoiadas na lei que define o crime de racismo e consequentemente pune sua prática.

${ }^{9}$ Cujo objetivo é garantir o reconhecimento de especificidades e a valorização da cultura negra, os quilombos é um exemplo deste tipo de reconhecimento.

${ }^{10}$ Políticas que se fundamentam na existência de desigualdades raciais aplicando critérios de reconhecimento, os quilombos também se enquadram nesse ponto.
} 
mento Negro) e a sociedade civil, com objetivo de contextualizar estratégias e planos formais para esses territórios e seus sujeitos.

Em 2003, o Estado brasileiro atendeu a uma reivindicação histórica do movimento negro ao construir a Secretaria Especial de Políticas de Promoção da Igualdade Racial - SEPPIR. Todavia, no contexto de quilombos, cujos direitos não são só formais, mas de cidadania, observa-se que tal superação dos entraves jurídicos ainda não foi devidamente solucionada, ao contrário, continua representando um grande obstáculo, tanto no processo de titulação do território quanto em outras políticas públicas.

Com a ativação da SEPPIR, em 2004, foi criado o Programa Brasil Quilombola - PBQ, que tem por finalidade coordenar as ações governamentais, por meio de articulações transversais, setoriais e interinstitucionais para as comunidades quilombolas e com ênfase na participação da sociedade civil. O programa é coordenado pela SEPPIR - em ação conjunta com vinte e três entidades da administração pública federal, sendo que é um programa que busca garantir o direito à terra, à documentação básica, à alimentação, à saúde, ao esporte, ao lazer, à moradia adequada, ao serviço de infraestrutura, à previdência social, à educação e à cultura, além de ser baseado na realidade e nas demandas das comunidades. Tal programa é vinculado ao Decreto $n^{\circ} 4.887 / 2003$, por meio da Subsecretaria de Políticas para Comunidades Tradicionais, além de outros setores e organizações sociais responsáveis pela execução de ações e do atendimento aos territórios quilombolas.

Como fruto da crescente pressão do movimento quilombola e inserida no quadro de forças políticas do fim do século XX a partir das mudanças na atuação do Estado nos governos Lula, frente às terras de quilombo, em 20 de novembro de 2003,o Decreto n 4.887 foi sancionado e por meio da regulamentação do artigo 68, o que trouxe avanços importantes na questão formal. Por exemplo, no dia 01/11/2010, o Quilombo de Ivaporunduva, localizado no Vale do Ribeira, no munícipio de Eldorado -SP, conforme informações dos próprios quilombolas residentes desse local, "a população comemorou com muita festa o título de reconhecimento do seu território. As famílias receberam do ex-presidente da república Luiz Inácio Lula da Silva, em 20 de novembro de 2010, o decreto de reconhecimento por Interesse Social"11.

Entretanto, esse decreto de 2003 sofreu a ofensiva direta da bancada ruralista e evangélica, através da Ação Direta da Inconstitucionalidade (ADI), proposta pelo Partido da Frente Liberal - PFL em 2004, já que "o partido alegou a inconstitucionalidade do Decreto, sustentando que ele seria formalmente inconstitucional por conta da inexistência de uma lei prévia que confira validade ao Decreto, que é ato normativo secundário"12. Outra questão importante em relação à situação legal dos quilombos é o artigo $2^{\circ}$ do Decreto $n^{\circ} 4887$, de 20 de novembro de 2003, que informa:

Consideram-se remanescentes das comunidades dos quilombos, para fins deste Decreto, os grupos étnico-raciais, segundo critérios de autoatribuição, com trajetória histórica própria, dotados de relações territoriais específicas, com presunção de ancestralidade negra relacionada com a resistência à opressão histórica sofrida. $\int 1^{\circ}$ Para os fins deste Decreto, a caracterização dos remanescentes das comunidades dos quilombolas será atestada mediante autodefinição da própria comunidade ${ }^{13}$ (PROGRAMA BRASIL QUILOMBOLA, 2007, p. 46).

\footnotetext{
${ }_{11}$ Depoimento oral concedido por quilombolas de Ivaporunduva, no dia da festa do título, 21/11/2014.

12 Conectas Direitos Humanos, 2014, p. 1. Disponível em: < http://www.conectas.org/pt/acoes/stf-emfoco/noticia/ 19096-adi-3239-comunidades-quilombolas>. Acesso em: 18 dez. 2018.

13 Texto retirado do Programa Brasil Quilombola que foi incorporado ao Plano Plurianual (PPA) desde 2004, com priori-
} 
$\mathrm{Na}$ sequência, o decreto $\mathrm{n}^{\circ} 4887$, define as formas de autoafirmação que os órgãos responsáveis pela certificação, demarcação e titulação do território têm de seguir, sem esses fins de decreto, não há a possibilidade de certificar os quilombos pela FCP e nem a titulação e desapropriação do INCRA - SP. É importante salientar que, a antes desse Decreto, competia à FCP a emissão da certidão de autodefinição.

Em São Paulo, a instituição que elaborava o Relatório Técnico-Científico - RTC e a demarcação dos territórios quilombolas era o ITESP, como já foi frisado. Atualmente, só em algumas situações que esse instituto ainda faz as demarcações, mas, na maioria das vezes fases, em territórios que estejam em áreas devolutas, os Relatórios Técnico-científicos, feitos pelo Instituto de Terras do Estado de São Paulo, foram transferidos para o INCRA.

Desde 2003, a demarcação fica sob o dever do INCRA, que passa a ser responsável por todos os procedimentos do Relatório Técnico de Identificação e Delimitação - RTID, abordando informações geográficas, ecológicas, cartográficas, fundiárias, agronômicas, históricas e socioeconômicas do território, além de ser também responsável pelo Relatório Antropológico, que é um dos eixos integrantes do RTID. Tais informações são obtidas junto aos quilombolas em campo.

O INCRA não tem outras políticas a não ser a de demarcação. Ainda, outro aspecto no processo da demarcação é a cadeia dominial, que é diferente da cadeia dominial feita para a reforma agrária, já que essa cadeia para regularização de quilombo deve ser completa, voltando-se à origem do título de domínio do território étnico quilombola, por meio das histórias orais dos mais velhos, assim, descobrindo se o território foi comprado ou se foi doação, etc. A seguir, o (Mapa 1) demonstra a porcentagem de comunidades negras rurais quilombolas localizados em cada Estado brasileiro.

zação de ações, destinação de recursos e definições de metas de cada órgão da administração pública federal para as comunidades quilombolas (PROGRAMA BRASIL QUILOMBOLA, 2007, p. 8). 


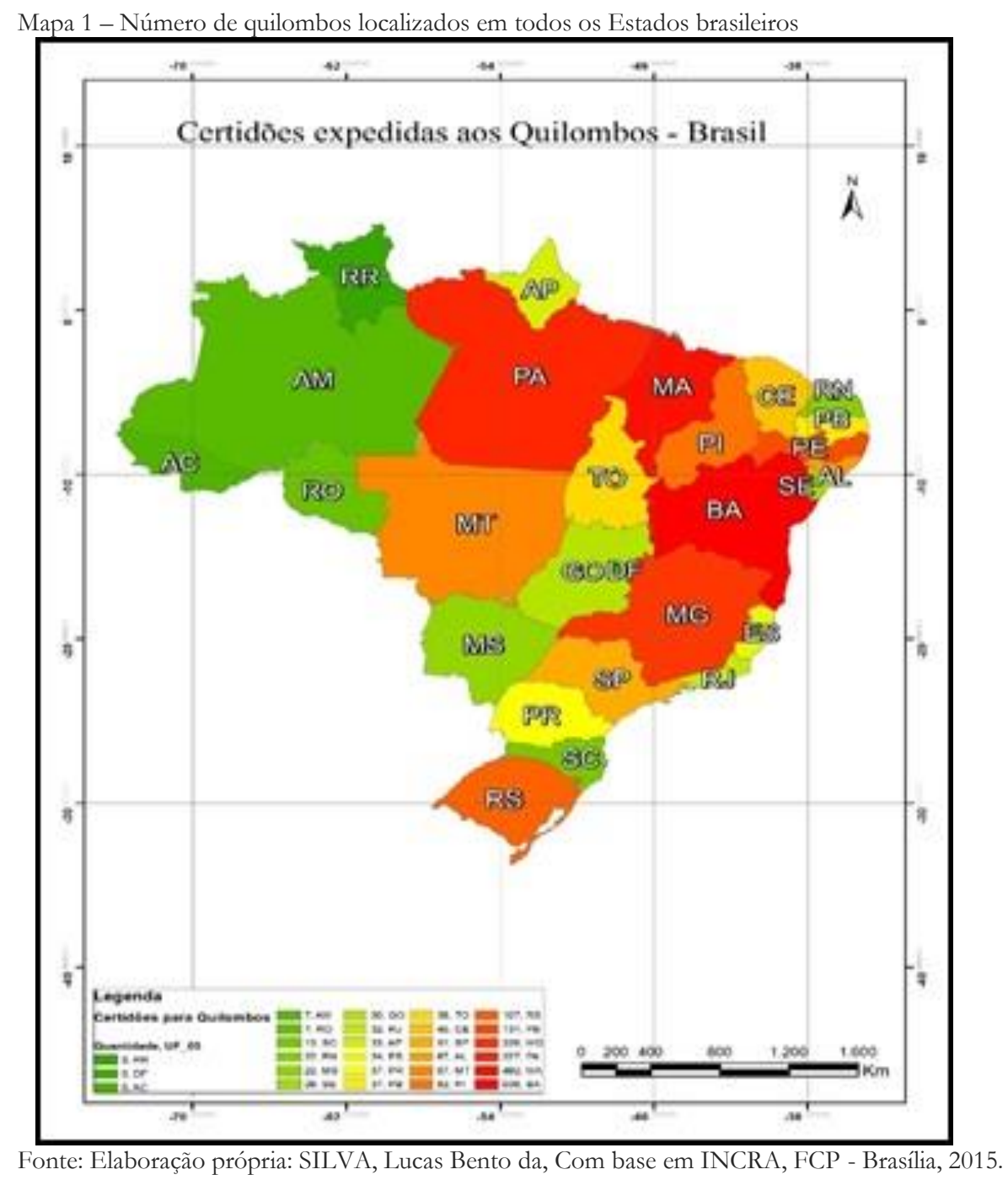

No mapa acima é possível ter uma ideia da escala de evolução de reconhecimento dos territórios étnicos quilombolas no governo LULA, que era de 150 títulos, até junho de 2015, os dados FCP totalizavam 2607 quilombos certificados e atualmente 253 contam com o título de seu território, observa-se que as ações políticas do LULA têm abrangência nacional, já no governo de FHC, como já colocado, o total de títulos expedido foram de 46 e percebe-se que consiste com as políticas de caraterísticas mais regionais ou localizadas. Vale ressaltar que o acréscimo de territórios quilombolas titulados entre os governos de FHC e LULA foram de 100\%, nos governos LULA.

Portanto, o conjunto de finalidades a ser executado por meio das políticas públicas que estão descritas no Programa Brasil Quilombola (Quadro 1), são, em alguns pontos, demandas próprias dos quilombolas. Na maioria das vezes, são provocadas pelas organizações governamentais, que as relacionando com os respectivos recursos reservados para tais finalidades, por exemplo, via a Lei Orçamentária Anual - LOA ${ }^{14}$. Sendo assim, foi assinalado o estabelecimento

${ }^{14}$ A Lei Orçamentária Anual (LOA) - estima receitas e fixa despesas para um ano, de acordo com as prioridades contidas no PPA e LDO, detalhando quanto será gasto em cada ação e programa - Plano Plurianual (PPA) - lei que prevê a arrecadação e os gastos em programas e ações para um período de quatro anos - Lei de Diretrizes Orçamentárias (LDO) - estabelece as metas e prioridades para o exercício financeiro, orienta a elaboração do orçamento e faz alterações na 
de quatro eixos de ações, junto aos quilombos, no Programa Brasil Quilombola.

\begin{tabular}{|c|c|}
\hline Regularização Fundiária & $\begin{array}{l}\text { Resolução dos problemas relativos à emissão do título de posse das terras e é a base } \\
\text { para a implantação de alternativas de desenvolvimento, além de garantir a reprodução } \\
\text { física, social e cultural de cada comunidade; }\end{array}$ \\
\hline Infraestrutura e Serviços & Consolidação de mecanismos efetivos para destinação de obras de infraestrutura; \\
\hline Desenvolvimento Econômico e Social & $\begin{array}{l}\text { Modelo de desenvolvimento local, baseado nas características territoriais e na identi- } \\
\text { dade coletiva, visando à sustentabilidade ambiental, social, cultural, econômica e polí- } \\
\text { tica; }\end{array}$ \\
\hline Controle e Participação social & $\begin{array}{l}\text { Estímulo à participação ativa dos representantes quilombolas nos fóruns locais e naci- } \\
\text { onais de políticas públicas, promovendo o seu acesso ao conjunto das ações definidas } \\
\text { pelo governo e seu envolvimento no monitoramento daquelas que são implementadas } \\
\text { em cada município brasileiro. }\end{array}$ \\
\hline
\end{tabular}

Fonte: Elaboração própria: SILVA, Lucas Bento da, com base em PBQ, 2018.

O PBQ também procura manter parceria com as representações dos órgãos federativos nos estados, sendo essas representações na maioria das vezes burocráticas, a exemplo do INCRA, do Instituto Brasileiro do Meio Ambiente e dos Recursos Naturais Renováveis - IBAMA e da Fundação Nacional de Saúde - FUNASA, entre outros, no intuito de descentralizar e agilizar as respostas dos Governos para os territórios de quilombos. Então, os governos municipais têm, neste sentido, uma função singular, por se responsabilizarem, em última instância, pela execução de algumas políticas em cada território, onde se localizam os quilombos.

Entretanto, em algumas situações, essas parcerias não são fáceis de serem construídas com as prefeituras, isso por motivos que vão desde questões de origem preconceituosa ou até mesmo por razões que se explicam apenas por meio do entendimento do que seja o racismo institucional ${ }^{15}$. Apenas a critério de exemplo, entre tantos casos, citamos um fato ocorrido com alguns quilombolas do Quilombo Buriti do Meio, localizado na região norte do Estado de Minas Gerais, no município de São Francisco.

Diversas vezes os quilombolas dirigiram-se ao Prefeito - representante do poder público eleito pelo voto que deve por principio garantir os direitos e deveres de todos sem diferenciação de raça e pertencimento étnico - a fim de solicitar algum apoio, e em uma situação dessas escutaram o prefeito dizer, "quando não é os índios, são vocês negros que vêm tumultuar a prefeitura e a cidade" (Relato coletado na reunião com o Prefeito de São Francisco e os quilombolas do Quilombo Buriti do Meio, sobre política pública repassado do Governo Federal para o município 14/04/2009).

Geograficamente, tais políticas públicas “ajudam” a rever as complexidades históricas que existem no território brasileiro, cujo cenário inclui as disputas territoriais e os conflitos que introduzem todo o contexto agrário mal resolvido no Brasil. Porém, é importante ressaltar que essas políticas ainda não foram capazes de trazer muitas respostas concretas quanto ao quadro sociogeográfico que se propõem a modificar, "por motivos em geral de ordem burocrática/jurídica do próprio Estado brasileiro, que deu poucos passos quanto à resolução da questão

legislação tributária (PROGRAMA BRASIL QUILOMBOLA, 2007, p. 8).

${ }^{15}$ Configura-se na prática discriminatória dos sistemas de trabalho, direito, saúde, educação, economia, política e moradia. Esse tipo de racismo é a institucionalização de crenças racistas e individuais. Se há consequências racistas das leis, das práticas ou dos costumes institucionais, a instituição é racista, independentemente do fato dos indivíduos que mantém tais práticas terem ou não, intenções racistas (INSTITUTO BRASILEIRO DE ANÁLISES SOCIAIS E ECONÔMICOS. Disponível em: <http://ibase.br/pt/?s=racismo+institucional>. Acesso em: 19 dez. 2018. 
concernente à reforma agrária” (SILVA, 2011, p. 50).

A ampliação do escopo e da cobertura da política social no Brasil, processo este dinamizado a partir da Constituição Federal de 1988 (CF/88), vem ensejado esforços crescentes do campo de monitoramento e avaliação de programas sociais no país. Contudo, em que pesem tais esforços de aprimoramento, é preciso reconhecer que a proposição de sistemas de monitoramento para acompanhar as ações e os programas governamentais e a especificação de pesquisas de avaliação destes últimos ainda padecem de uma série de dificuldades (JANNUZZI, 2011, p. 1).

As disputas territoriais são fatos mediados por instâncias do Estado, devido sua representação em escala maior de parlamentares latifundiários, que manipulam as decisões no reconhecimento das diversidades no campo, no sentido de totalizar a espacialização e territorialização da política do agronegócio. Sendo assim, tais leis são um aspecto positivo, no sentido da visibilidade, por motivos de mobilizações, organizações e ações dos movimentos sociais que integram tais lutas, contra o modelo de desenvolvimento desigual dos grupos economicamente dominantes. Desde a criação da legislação específica, houve alguns avanços em algumas regiões do Brasil, mas o que se vê na conjuntura da aplicação dessas leis é a fragmentação e lentidão das ações dos órgãos responsáveis para aplicação das políticas.

\section{CONSIDERAÇÕES FINAIS}

Nestas considerações finais, reafirmamos os desafios encontrados durante o exercício de teorizar e contextualizar as especificidades e a espacialização dos quilombos nas Américas e os programas e as ações políticas. Assim, os pontos levantados na contextualização das dinâmicas das políticas públicas para quilombos nos governos de FHC (1995-2002) e LULA (20032010) contribuirão na reflexão das limitações e avanços dos programas e ações para quilombo, o que faz parte de um processo geográfico, histórico e concreto do não respeito aos seus direitos. E no governo FHC, como se vê, as políticas foram mais culturais, enquanto no governo LULA, as políticas públicas são distributivas e, para os quilombos, com intuito valorativo/identitário.

Ressaltamos que as categorias e conceitos foram colocados de modo a mostrar especificidades das formações dos quilombos nas Américas e o trajeto da concretização das políticas públicas específicas para Quilombo - abordando o conceito de território étnico (tradicionalmente ocupado), sendo que as espacializações dos Quilombos no Brasil somam-se às novas questões sobre o conflito agrário no Brasil. Ainda, boa parte dos territórios quilombolas ainda não é reconhecida pela esfera jurídica, como decretos ou instrumentos normativos, os quais lhes assegurem a regularização territorial. Por isso, a maioria das comunidades tradicionais têm se amparado em políticas das Reservas de Desenvolvimento Sustentável, das Reservas Extrativistas, dos Assentamentos da Reforma Agrária, entre outros modos, para manter parte dos seus territórios tradicionais, como exemplo, é a situação dos indígenas.

No entanto, o governo interino de Michel Temer, através do Decreto 8.780/30 de maio de 2016, transferiu as secretarias do Ministério do Desenvolvimento Social e Agrário e o Instituto Nacional de Colonização e Reforma Agrária - INCRA para a responsabilidade da Casa Civil, essa medida é um retrocesso para as cidadanias quilombolas e para a sociedade brasileira, pois não deixa claro as funções dessas entidades na Casa Civil e até o momento não foram discutidos os programas e ações. Embora percebendo os diversos caminhos abertos pela pesquisa 
realizada, apontamos a necessidade de continuidade de análises em futuros trabalhos acadêmicos com a finalidade de aprofundar os conteúdos geográficos e as políticas públicas para quilombos na direção do entendimento mais amplo das políticas e das "atuais" categorias sociais nas disputas territoriais e dos conflitos no campo.

\section{REFERÊNCIAS}

ANJOS, Rafael Sanzio Araújo dos. Cartografia étnica: a África, o Brasil e os territórios dos quilombos. In: VI ENCONTRO NACIONAL DA ASSOCIAÇÃO DE PESQUISA E PÓSGRADUAÇÃO EM GEOGRAFIA DO BRASIL, 1., 2005, Ceará. Encontro nacional da anpege. Fortaleza. p. $320-350$.

ARRUTI, José Maurício. Mocambo: antropologia e história do processo de formação quilombola. Bauru: EDUSC, 2006.

ALMEIDA, Alfredo Wagner Berno de. Capitalismo globalizado e recurso territorial: fronteiras da acumulação no Brasil contemporâneo. Rio de Janeiro: Lamparina, 2010.

BRASIL. Constituição Federal de 1988. Promulgada em 5 de outubro de 1988. Disponível em <http://www.planalto.gov.br/ccivil_03/constituicao/constituição.htm>. Acesso em: 18 dez. 2014.

DEMATTEIS, G. O território: Uma oportunidade para repensar a geografia. In: SAQUET, M. A. Abordagens e concepções sobre território. São Paulo: Expressão Popular, 2007.

FERNANDES. Bernardo Mançano. Movimentos socioterritoriais e movimentos socioespaciais: contribuição teórica para uma leitura geográfica dos movimentos sociais. Revista Nera, Presidente Prudente v. 2 n.6 p. 14 - 34, jan/jun 2005.

FREYRE, Gilberto. Casa-grande \& Senzala: formação da família brasileira sob o regime da economia patriarcal. Porto Alegre: Globo, 2003.

JANNUZZI, P. M. Avaliação de programas sociais no Brasil: repensando práticas e metodologias das pesquisas avaliativas. Planejamento e políticas públicas, Brasília, v.6, n. 36, jul. 2011.

LANDER, Edgardo. A colonialidade do saber: eurocentrismo e ciências sociais. In: Perspectivas latinoamericanas. Buenos Aires, Argentina: CLACSO, set. 2005. (Colección Sur Sur). LIMA, Márcia. Desigualdades raciais e políticas públicas: ações afirmativas no governo Lula. Novos estud. - CEBRAP, São Paulo, n. 87, p. 76 a 95 jul. 2010.

LITTLE, Paul. Territórios sociais e povos tradicionais no Brasil: por uma antropologia da territorialidade. Brasília: UNB, 2002. (Série Antropológica, 322).

MARINHO, Thais Alves. Continuidades e rupturas: políticas para quilombolas. Desigualdade \& Diversidade - Revista de Ciências Sociais da PUC-Rio n. 14, jan/jun, 2014, pp. 154193.

MUNANGA, Kabengele; GOMES, Nilma Lino. O negro no Brasil de hoje. São Paulo: Global Editora, 2006.

MUNANGA, Kabengele. Origem e histórico do quilombo em África. In: MOURA, Clóvis (Org.). Os quilombos na dinâmica social do Brasil. Maceió: EDUFAL, 2001. p. 57-63.

MOURA, Clóvis. Quilombo resistência ao escravismo. São Paulo. Ed. Ática, 1993.

NERES, Júlio Maria et al. Economia de palmares. In: MOURA, Clóvis. Os quilombos na dinâmica social do Brasil. Maceió: EDUFAL, 2001. p. 40 - 55.

OLIVEIRA, Manuel Zapata. El árbol brujo de La libertad, África em Colômbia: Orígenes- 
transculturación- presencia. Bogotá, Desde abajo, 2014.

PINTO, Viviane Cristina. De Fernando Henrique Cardoso a Lula: uma análise das políticas públicas de cultura no Brasil. 2010. Disponível em: <http://myrtus.uspnet.usp.br/celacc/sites/default/files/media/tcc/178-584-1-PB.pdf>. Acesso em: 19 jan. 2016.

PROGRAMA BRASIL QUILOMBOLA, 2007, p. 8. Disponível em: < http:/ /www.portaldaigualdade.gov.br/portal-antigo/.arquivos/pbq.pdf>. Acesso em: 19 jan. 2016.

REIS, João José; GOMES, Flávio dos Santos. Liberdade por um fio: história dos quilombos no Brasil. São Paulo: Companhia das Letras, 1996.

SANTOS, Milton. Técnica, espaço, tempo: globalização e meio técnico-científicoinformacional. São Paulo: Hucitec, 1996.

SILVA, Simone Rezende da. Negros na mata atlântica, territórios quilombolas e a conservação da natureza. 2008. 370 f. Tese (Doutorado em Geografia) - Faculdade de Filosofia, Letras e Ciências Humanas, Universidade de São Paulo, São Paulo, 2008.

SOUZA, Bárbara Oliveira. Panorama histórico, identidade e política do Movimento Quilombola Brasileiro. 2008. 204 f. Dissertação (Mestrado em Antropologia Social) - Instituto de ciências sociais, Universidade de Brasília, 2008.

WILLIAMS, Eric. Capitalismo e escravidão. São Paulo: Companhia das Letras, 2012. 